\title{
Talent Management and Knowledge: Theory, Methodology, Models
}

\author{
Ludmila Viktorovna Orlova ${ }^{1}$, Yuri Alekseevich Afonin $^{2} \&$ Viktor Vladimirovich Voronin ${ }^{2}$ \\ ${ }^{1}$ Samara Academy of Municipal and State Management, Samara, Russian Federation \\ ${ }^{2}$ Samara State Univerrsity of Economics, Samara, Russian Federation \\ Correspondence: Ludmila Viktorovna Orlova, h.141, fl. 69, 6 Proseka, Samara, 443124, Russian Federation. Tel: \\ 7-927-741-0395. E-mail: Orlovalv313@mail.ru
}

Received: March 11, 2015 Accepted: March 30, 2015 Online Published: May 22, 2015

doi:10.5539/res.v7n9p75 URL: http://dx.doi.org/10.5539/res.v7n9p75

\begin{abstract}
Talent management involves the practice of continuously discovering, developing, using and retaining those people in an organization, which are especially valuable either in terms of having a great potential for the future of the organization, or because they are capable of resolving business and operational issues which are critical for the company. The knowledge management system includes all of the interacting and interdependent elements that pertain to monitoring and controlling knowledge (including processes, databases, supporting software, organizational structures, etc.) and that participate in allowing the company achieve its goals.
\end{abstract}

Keywords: talent management, human resource management, talent management effectiveness assessment, talent acquisition, talent development, storing the knowledge, supporting knowledge exchange, creating knowledge, evaluating knowledge, using knowledge, selling knowledge

\section{Introduction}

\subsection{Introduction the Problem}

Talent Management (Eng. Talent management) - a set of tools of personnel management that enable organizations to attract, retain and effectively use staff who make a significant contribution to the development organizatsii. Termin talent management, which emerged in the 1990s, encompasses activities personnel management to involve employees in the innovation process, the formation of creative stimuli and develop the creative potential of employees.

Knowledge Management (Eng. Knowledge management) - a systematic process by which are created, stored, distributed and used the basic elements of intellectual capital needed for the success of the organization; strategy, transforming all kinds of intellectual assets in higher productivity, efficiency and new value.

\subsection{Importance of the Problem}

Learning organizations use the concept of talent management. This is a system of managing personnel in order to build competitive advantages by focusing on monitoring, developing, using and retaining talented workers who can effectively resolve complex business issues and who are able to grow into managing positions.

\section{Relevant Scholarship}

The term "talent management" was first introduced in 1997 in the book titled "The War for Talent" by McKinsey consultant Elizabeth Axelrod, Ed Michaels, and Helen Handfield-Jones (Bellinger, 2013). They analyzed the results of a large volume of research performed by the McKinsey group to determine who relationships with employees affect the success of a company. Using reliable research material, the authors convincingly demonstrated that successful companies do not only improve the procedures and regulations governing human capital management, but themselves prove to be highest sought commodities on the labor market, because they do everything possible to attract, develop and retain the most talented workers at all levels of the management hierarchy. In this specific case, "talent" refers to the ability of the employee to reach exceptional results which are acknowledged and awarded by the owners, managers and consumers. Talented people are the ones who can change the operations of the company either by making one major contribution to the company, or by performing high quality work and expressing potential over a long period of time. If an employee's talents are not needed, the risk of his leaving increases dramatically, which in turn may adversely affect the company's competitive edge (Davenport, 1994). 


\section{State Hypothesis and Their Corresponding to Research Design}

The main goal of talent management is to help the company become a highly effective and self-sustaining organization which emphasizes a quick reaction time and strict adherence to its business goals (University of North Carolina at Chapel Hill, 2007).

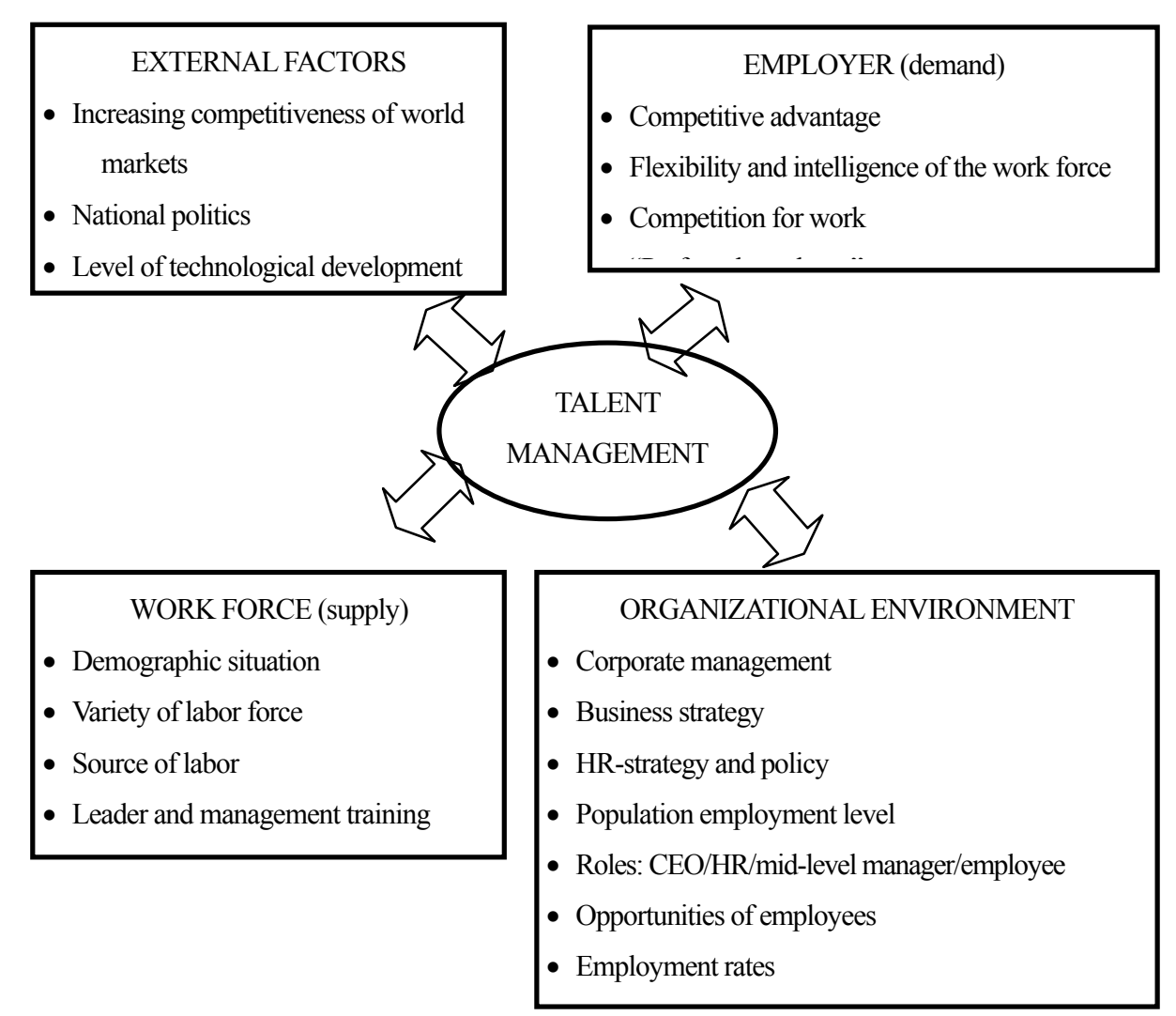

Figure 1. Supply, demand and external factors in talent management

\section{Method}

Talent management as a process can be understood as a cycle with the following components:

- Talent management strategy (planning)

- Recruiting

- Effective management

- Training and development

- Planning of achievements

- Leadership training

- Motivation 


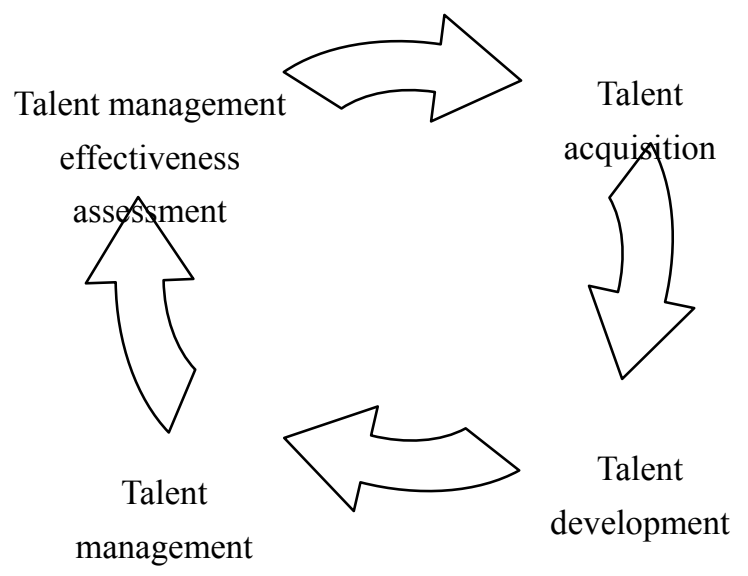

Figure 2. Talent management cycle

The concept of talent management is grounded on developing an employee in order to find and reveal his or her potential. Talent management is a way to make work interesting for your employees.

Human resource management is a tool which is transformed by changes within the market. The times when a company knew what it was going to produce in five years and how it was going to develop in ten years are gone. Today the market demands new instruments for raising the effectiveness and retention rates of leaders within companies.

Talent management is introduced by companies whose success is grounded on the ability to react quickly to a changing market and to implement innovative products and technologies. The competitive advantages of such companies prove to be a better qualified personnel, which in turn allows the company to better meet the volatile demands of the market and clients, to develop new products with a shorter turn-around time, to outperform its competitors in terms of service, etc. (Nonaka, 1991)

\section{Result}

At the same time talent management provides a high return to companies with a flexible structure and a highly developed system of horizontal and vertical rotation where priorities are given to teams aimed at achieving results in a particular field. The responsibilities of the employees are determined by the requirements of the business. Talent management assumed that all company managers are involved in this process and that original, non-standard approaches are used by them when working with the rest of the personnel. Not all organizations are capable of making such a major internal overhaul, and not all managers are ready to dedicate the largest portion of their time to developing their subordinates. After all, it is easier to find talent than to create an atmosphere which would allow the talent to achieve high results (Nonaka, 2009).

In order to introduce a management technology which would focus on continuously discovering talent within the personnel and using it the best way possible for the benefit of the company, certain key principles need to be maintained. First of all, the company should pay deliberate attention to talent: each manager needs to take personal responsibility to create talent. Second: job offering should attract new, talented employees; the work should be valuable for them. Third: hiring conditions should be modified. A company should take the initiative in seeking out talent. This should be done constantly, and should not depend on the availability of open positions. Fourth: the company should also support continued education and training of its personnel, which is to be aimed at developing talent. In a perpetually changing atmosphere training also, inevitably, becomes continual. Fifth: the personnel should be differentiated, because when all of the employees are leveled out, the talented workers begin to feel the uselessness of putting forth extra effort. Therefore, if a manager would like to attract or keep talent, he or she should create an atmosphere in which talented specialists differ from one another. This is achievable by creating a system for evaluating personnel to flush out talent, which in turn affects the system of motivation. As a result, a system of supporting talented employees is formed. Sixth: leadership should be developed. The top management needs to think about creating a system for growing mid-level managers (this is called leadership management) (Bellinger, 2013). 
All employees are tapped into when the company searches for hidden talent, and if the specifically needed competencies are not found within, the hiring process begins to attract talent from the outside. The main difficulty is identifying talent. Companies are not always able to accurately verbalize their requirements to potential employees, which in turn complicated the development of a personalized growth plan. The idea behind talent management has to do with identifying talented employees within an organization, and then finding a use for their talents, be it via a specific position or project. In other words, managers should determine the areas in which employees are especially proficient, and then help those employees develop their professional and leadership skills (Anonymous, 2013).

Each of the employees who've been placed into the talent pool gets assigned a coach or a mentor. Training addresses the immediate activities of the company, including independent work, participation in projects, and group efforts. Priority is given not to traditional training approaches, but to obtaining knowledge from colleagues, mentors and other people; i e. informal training with continuously more complicated tasks (Anonymous, 2013).

Within the talent management system the employee is always evaluated based on feedback from the coach. Key company managers meet regularly to discuss the results of the employees who comprise the talent pool, review the possible paths for their furthered development, and propose possible candidates for rotation or promotion. The success criteria is determined by work results and demonstrated leadership skills. Such a complex system cannot be structured and maintained by the HR department and immediate managers alone. It should be embedded into the business processes of the company and only then will it bring about positive change (Anonymous, 2013).

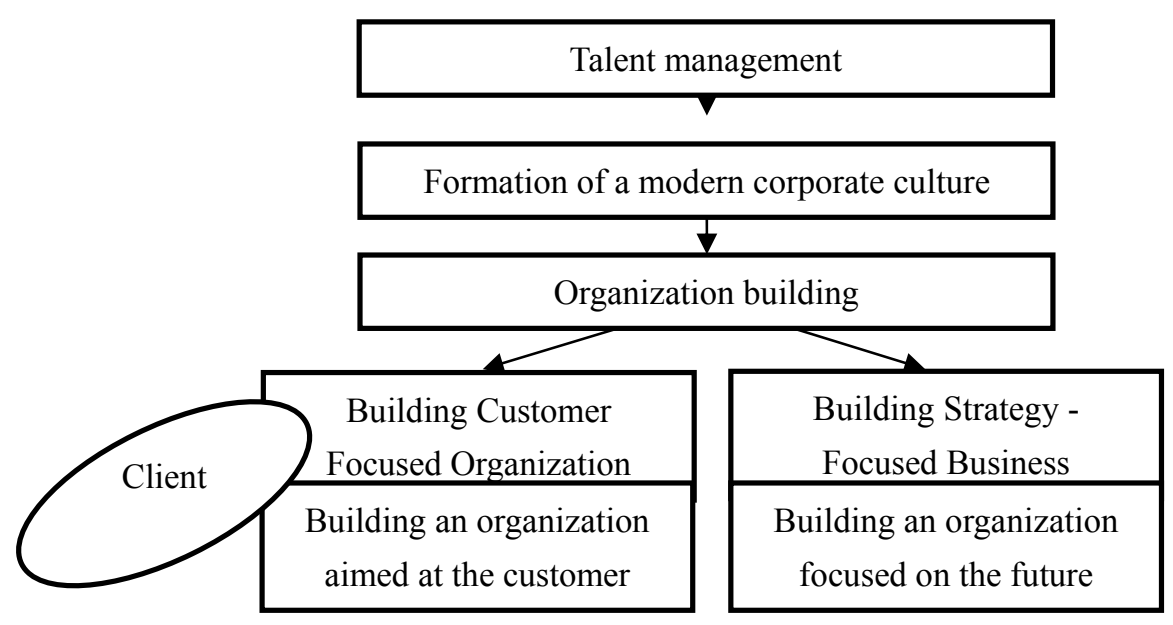

Figure 3. Conceptual foundations for organizing the future

Negative experience gained from the economic crisis has caused us to rethink our approach to human resource management overall, and to talent management in specific. Today, given that the crisis looks to be over, companies find that employees who successfully combine developed competence and experience are becoming more and more valuable. The new term "experiential talent" has been coined to describe talent which blossoms slowly and which demands extensive experience before it can begin to bring fruit. People demonstrating this type of talent are the cornerstones of successful organizations. And this concept is very close to the Russian mentality and Russian companies. Many young top managers in Russia are very familiar with the idea of talent management, and readily support non-standard, brilliant, talented people, to pull them to the top and capitalize on their abilities (Addicot, McGivern, \& Ferlie, 2006).

The life of a learning company is not possible without knowledge management. As a rule, the establishment of contacts and the exchange of information between company departments is an area that demands special effort and attention. The concept of "knowledge management" was born in the mid 1990's in large corporations where the problem of processing information because particularly acute. It turned out that without timely processing the information, accumulated by company specialists and intended to be used as an advantage over competitors, becomes outdated and useless. But if knowledge is quickly distributed, obtained or exchanged, it generates new knowledge and raises the competitive edge of the company by improving and creating new products (Sharma \& Gupta, 2004). 
The United States, Japan and west European countries have been promoting principles for management of economic issues based on full access to information. And thanks to the results they achieved, they can now categorize their societies as post-industrial information-based communities; societies of knowledge.

An information-based society, a society of knowledge, is first and foremost a community of freely convertible technologies used for scientific, environmental, and social development. In developed countries of the West a high quality of life is achieved through the annual economic growth of $80-95 \%$ thanks to the development of new technologies. As a result, the most profitable and attractive areas of investment are the development of high technologies and service, which quickly pay for themselves, decrease the dependency on raw materials, and give the investors the opportunity to conquer new goods and services niches.

Western countries have won a strategic niche in the high technologies markets, which allows them to move away from creating material-dependent goods which also pose higher risks to the environment. This change has led to the realization that an organization's value is not measured merely by its material and financial assets, produced goods and property, but by the experienced, qualified employees and their loyalty, know-how, culture, etc; in other words, everything that comprises "intellectual capital". The ability to assess, accumulate and develop intellectual capital, and to use it to help an organization reach its goals, has become a key priority for maintaining the steady growth of a company in the cut-throat competitive climate today.

The concept of "intellectual capital" gives an economic price-tag on knowledge which a company has. In order to understand what intellectual capital means in an economic setting, often the following example is used: Imagine that most of the key employees have left a programming company. Then the drop in the cost of that company's shares will equal the amount of intellectual capital the company. The main models of intellectual capital divide it into three components: human capital, including any personal, subjective knowledge, organizational capital, including objective knowledge, and relational capital, which is the total of all of the connections established with all of the company's entourage, especially the clients.

Therefore, if knowledge can be perceived as a sort of intellectual capital, then this capital (just as financial capital) can be "owned" or "borrowed". But the knowledge itself is not an asset because it belongs to the employees, which are not company property. So a major task of knowledge management becomes the conversion of this intellectual capital into intellectual assets - the objectification of knowledge, and its retrieval from its sources, which are the individual employees.

There are two widely accepted approaches to managing knowledge (Maier, 2007).

The first approach can be called personalized or intuitive. This approach is based on the fact that knowledge is embedded within people, and so the most important thing is for those people (the experts) to be wardens of the knowledge, to keep it and share it. From this follows the need to motivate the personnel and develop an appropriate company culture. The key task of the management in this case is to discover, store, and effectively use employees' knowledge.

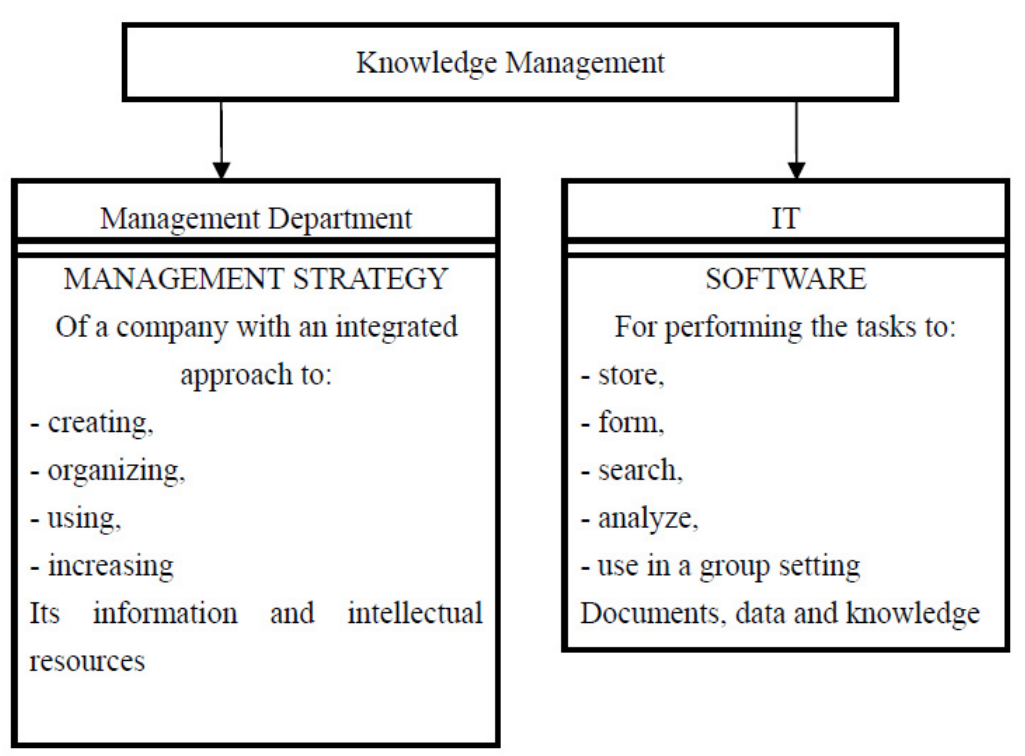

Figure 4. Knowledge management: Two central aspects 


\section{Discussion}

The second approach is information or technology-based. This approach is based on the fact that contemporary organizations have accumulated large data-bases of information (about scientific developments, clients, vendors, operations, and much more), stored in dozens of operation and transaction systems in different functional departments. These databases conceal real pearls of wisdom. But most of the information is typically unprocessed data unusable for analysis. In order to find real knowledge in large databases and to process it, a company needs the appropriate information technologies which reveal hidden relationships and patterns within data. Knowledge is perceived as specific information on a given topic. The system which can provide a concrete response to a question is a system which successfully manages knowledge (Sanchez, 1996).

The relevance of this type of management is supported by a couple of fundamental facts:

1) The rapid pace at which knowledge becomes outdated as new discoveries happen day after day. This rate of innovation demands that the management of a company provide an adequately quick reaction to the changes that are brought about as a result.

2) Major changes in the labor market: people have become more mobile and can easily move from place to place if their job demands it.

In today's conditions even the Japanese custom of hiring for life has ceased to be relevant while the portfolio-based career of field specialists is becoming the in-demand norm. The principles of outsourcing are also gaining momentum, and parents organizations hire outside firms, vendors and specialists in narrow fields to perform specified tasks.

A problem arises: how do you retrieve knowledge from the work force? The work force in Russia is aging. Some of the enterprises with a rich background, which have invested means to build-up their intellectual potential, are aging as well. In these companies knowledge, as a rule, is stored in the heads of its employees - those same employees who are soon retiring. This raises the issue of maintaining and keeping the intellectual capital of a company. The answer to this dilemma is found through knowledge management. One of the most important functions of knowledge management is to turn intellectual capital into intellectual assets, to objectify knowledge, to extract it from the workers who are its source. Only then will the dependency of an organization on the knowledge of a specific individual will decrease, and knowledge will be freely transferable and effectively used for the interests of the company (Sanchez, 1996).

Moreover, the safekeeping and expansion of intellectual capital assumes continuous training and specialized education, which enriches knowledge. (University of North Carolina at Chapel Hill, 2007)

The other reason why knowledge management is so important today is the phenomenon of "brain drain", which practically all organizations encounter. In order to minimize loses it's important to organize the exchange of knowledge in a way that would prevent the company from being hurt if a valued specialist left. The knowledge available to a company should be stored in the organization's "corporate memory".

Table 1. Spreadsheet of knowledge management strategies

Machine Search for new patterns in information databases. Formalization and accumulation of knowledge Imitation modeling

in a corporate database

Person Activation of the personal potential of the Continued training of employees and transfer of employees to generate new ideas experience

Generation of new knowledge

Accumulation of existing knowledge

A final aspect of knowledge management is the dissemination and sales of knowledge. This is why the useful information that a company possesses is called intellectual property or intellectual assets.

In order to accomplish this successfully, the following principles should be applied: knowledge should be protected and assessed, and the technologies used to transfer knowledge should be in place.

All of the above systematically creates an independent sphere of managerial activity, aimed at controlling and monitoring intellectual capital of an organization in order to establish a solid competitive advantage through 
knowledge management. Through this type of management an organization can adapt to the constantly changing conditions of the surrounding business environment by maintaining the necessary level of competency among the employees and by forming a solid competitive edge (Wright, 2005).

\section{Conclusion}

Knowledge management means, first of all, the control of intellectual capital, which includes the following tasks:

- To achieve the organization's goals by increasing the intellectual capital and using it effectively

- To increasing the effectiveness of the decisions made

- To create causes for innovation

- To use benchmarking in all spheres of activity; this includes sharing information about the success of competitors and comparing these results with the company's own progress

- To train and motivate employees

- To boost the effectiveness of manufacturing, procurement and marketing processes

The tasks delegated to knowledge management teams also include the support of the following processes:

- Identifying the owners of key knowledge and information within a company, and retrieval of this knowledge

- Storing the knowledge

- Supporting knowledge exchange

- Creating knowledge

- Transferring knowledge, ensuring that new knowledge is processed and absorbed

- Renewing knowledge

- Evaluating knowledge

- Using knowledge

- Selling knowledge (Nonaka, 2009).

The knowledge management system includes all of the interacting and interdependent elements that pertain to monitoring and controlling knowledge (including processes, databases, supporting software, organizational structures, etc.) and that participate in allowing the company achieve its goals (Booker, Bontis, \& Serenko, 2008).

To summarize, the main goal of knowledge management is to change intellectual capital into intellectual assets, and to obtain it from its sources - from the workers who possess it. Then the risk of losing valuable information will be reduced, and information will be freely transferred, exchanged, and used effectively to promote company interests.

Thus, talent management and knowledge management necessary and sufficient condition for the innovative development of the organization in the context of globalization. And if the authors have advanced a step in solving this problem, then the goal would be achieved.

\section{References}

Addicot, R., McGivern, G., \& Ferlie, E. (2006). Networks, Organizational Learning and Knowledge Management: NHS Cancer Networks. Public Money \& Management, 26(2), 87-94. http://dx.doi.org/10.1111/j.1467-9302.2006.00506.x

Bellinger, G. (2013, April 18). Mental Model Musings (Systems Thinking Blog) (p. 34).

Booker, L., Bontis, N., \& Serenko, A. (2008). "The relevance of knowledge management and intellectual capital research". Knowledge and Process Management, 15(4), 235-246. http://dx.doi.org/10.1002/kpm.314

Columbia University's M. S. in Information and Knowledge Strategy (p. 194). (2013, November 21).

Davenport, T. H. (1994). Saving IT's Soul: Human Centered Information Management. Harvard Business Review, 72(2), 119-131.

Gupta, J., \& Sharma, S. (2004). Creating Knowledge Based Organizations (p. 90). Boston: Idea Group Publishing. http://dx.doi.org/10.4018/978-1-59140-162-9

Haifa Univeristy's KM Master of Science (p. 69). (2015, January 12). 
Maier, R. (2007). Knowledge Management Systems: Information and Communication Technologies for Knowledge Management (3rd ed., p. 295). Berlin: Springer.

Nonaka, I. (1991). “The knowledge creating company”. Harvard Business Review, 69(6), 96-104.

Nonaka, I., \& von Krogh, G. (2009). "Tacit Knowledge and Knowledge Conversion: Controversy and Advancement in Organizational Knowledge Creation Theory”. Organization Science, 20(3), 635-652. http://dx.doi.org/10.1287/orsc.1080.0412

Sanchez, R. (1996). Strategic Learning and Knowledge Management (p. 183). Chichester: Wiley.

Sanchez, R. (1996). Strategic Learning and Knowledge Management (p. 205). Chichester: Wiley.

University of North Carolina at Chapel Hill. (2007, March 19). Introduction to Knowledge Management (p. 371). Retrieved September 11, 2014, from http://www.unc.edu

Wright, K. (2005). Personal knowledge management: Supporting individual knowledge worker performance. Knowledge Management Research and Practice, 3(3), 156-165. http://dx.doi.org/10.1057/palgrave.kmrp.8500061

\section{Copyrights}

Copyright for this article is retained by the author(s), with first publication rights granted to the journal.

This is an open-access article distributed under the terms and conditions of the Creative Commons Attribution license (http://creativecommons.org/licenses/by/3.0/). 